\title{
Speciation and availability of trace metal micronutrient in wetland soils and stream sediments
}

\author{
JINSHU YAN ${ }^{1}$, NEHA SHARMA ${ }^{1}$, ELAINE FLYNN ${ }^{1}$, \\ DANIEL GIAMMAR ${ }^{1}$, JEFFREY G CATALANO ${ }^{1}$, GRACE \\ SCHWARTZ $^{2}$, SCOTT C BROOKS ${ }^{2}$, PAMELA \\ WEISENHORN $^{3}$, KENNETH KEMNER $^{3}$, EDWARD \\ O'LOUGHLIN $^{3}$ AND DANIEL KAPLAN $^{4}$ \\ ${ }^{1}$ Washington University in St. Louis \\ ${ }^{2}$ Oak Ridge National Laboratory \\ ${ }^{3}$ Argonne National Laboratory \\ ${ }^{4}$ Savannah River National Laboratory \\ Presenting Author: jinshu@wustl.edu
}

Trace metals are essential for microbially-mediated biogeochemical processes occurring in anoxic wetland soils and stream bed sediments, such as denitrification, methanogenesis, and mercury methylation. Low availability of these elements may inhibit key components of anaerobic carbon and nitrogen cycling and contaminant transformations. The solid-phase speciation of trace metals likely plays an important role in controlling their bioavailability. Metal speciation is well studied in contaminated soils and sediments as well as those naturally elevated in trace metals. However, less is known regarding the chemical forms of trace metals in systems having concentrations similar to geological background levels. In this work, we have investigated trace metal concentrations, extractability, and solidphase speciation in three freshwater subsurface aquatic systems: marsh wetland soils, riparian wetland soils, and the sediments of a streambed. These systems displayed similar variations in dissolved and solid-phase trace metal concentrations, and the latter showed no correlation with major element compositions. All soils and sediments were dominated by quartz but varied in clay mineralogy as well as the organic matter content. Levels of extractable copper and nickel were similar among the sites but were highest for zinc in the marsh wetlands and for cobalt in the stream bed sediments. However, at most locations a substantial majority of the studied trace metals were not mobilized during extractions, indicating that the potentially available pools of metals are limited. Quantitative analysis of X-ray absorption near-edge structure spectra reveals similar metal speciation across all sites. Copper, nickel, and zinc speciation is dominated by sulfides minerals, adsorbed species, structural incorporation in clay minerals, and complexation by organic matter. The potentially available metal pool, as indicated by sequential extractions, lacked a clear relationship with bulk metal speciation. A substantial fraction of the trace metals occurred bound to reduced sulfur at every site despite large variations in total sulfur content of the soils and sediments. This consistent association demonstrates the critical role of sulfur in controlling metal speciation in freshwater subsurface aquatic systems. More broadly, the observations in this study suggest that trace metal speciation in such systems is consistently dominated by a small set of recurring components. 